\title{
Despertar para soñar: el "estallido social" desde la idea de paradoja en psicoanálisis
}

\author{
Waking up to Dream: The Social Outburst from the Idea of \\ Paradox in Psychoanalysis \\ O despertar para sonhar: a convulsão social desde o conceito \\ de paradoxo na psicanálise
}

Patricio Meneses Merino ${ }_{-} * *_{1,2}$

\begin{abstract}
RESUMEN
Se ensaya una lectura psicoanalítica del estallido social chileno de 2019, formalizado como "fenómeno sociopsíquico", desde la perspectiva de Cornelius Castoriadis, y como "acontecimiento", desde la perspectiva de Gilles Deleuze. Se plantea desde allí que el estallido social ha producido un sujeto sociopsíquico específico, identificado y analizado a partir del concepto de "paradoja", de Donald Winnicott. Se concluye que, mediante la tolerancia a las paradojas que ese sujeto plantea, puede dársele la oportunidad de que encuentre por sí mismo el malestar que lo causa y la posibilidad de elaborar sus causas políticas.
\end{abstract}

\begin{abstract}
This study offers a psychoanalytic reading of the 2019 Chilean social outburst, formalized as a socio-psychic phenomenon, from the perspective of Cornelius Castoriadis, and as an event, from the perspective of Gilles Deleuze. From there, it is stated that the social outburst has produced a specific socio-psychic subject, which is identified and analyzed based on the Donald Winnicott's concept of paradox. It is concluded that it is through
\end{abstract}

Palabras clave: violencia política, conflicto social, teoría winnicottiana, metapsicología, paradoja
Key words: political violence, social conflict, Winnicottian theory, metapsychology, paradox

\footnotetext{
* Av. Nueva Providencia 1881, of 316, patricio.meneses@mail.udp.cl

** Psicólogo Clínico, Pontificia Universidad Católica de Chile. Magíster en Psicología Clínica, Universidad de Chile. Académico en Psicodiagnóstico y Técnicas Proyectivas en Universidad Alberto Hurtado. Académico en Psicodiagnóstico Adultos, Universidad Diego Portales. Académico programa de Magíster en Psicoanálisis, Universidad Diego Portales. Correspondencia: patricio.meneses.merino@gmail.com
} 
tolerance to the paradoxes that this subject rises up, that he can be given the opportunity to discover for himself the discomfort that causes this awakening and the possibility of elaborating its political causes.

\section{RESUMO}

Realiza-se uma leitura psicanalítica da convulsão social chilena de 2019, formalizada como um "fenômeno sociopsíquico", na perspectiva de Cornelius Castoriadis e, como um "evento", na perspectiva de Gilles Deleuze. A partir daí, propõe-se que este momento de convulsão social produziu um sujeito sociopsíquico específico, identificado e analisado a partir do conceito de paradoxo de Donald Winnicott. Conclui-se que, através da tolerân-

Palavras-chave: violência política, conflito social, teoria winnicottiana, metapsicologia, paradoxo. cia aos paradoxos que esse sujeito apresenta, pode ser dada a ele a oportunidade de encontrar por si mesmo o desconforto que o causa e a possibilidade de elaborar suas causas políticas. 


\section{Introducción: el "estallido social" como acontecimiento}

Quienes vivimos en Chile hemos estado asistiendo, desde octubre de 2019, a una sucesión permanente de fenómenos y hechos de carácter político-social, a cuyo conjunto expeditamente se llamó "estallido social”, remarcando con ello el carácter sorpresivo de los hechos, y en aparente atención a fenómenos similares en otros países del mundo. Las protestas y movilizaciones, que la opinión pública experimentó como súbitas, se vieron acompañadas por diversos ataques a símbolos del poder económico, político y militar, y fueron repelidas de manera sistemática por las fuerzas de orden y seguridad, lo que incluyó violaciones a los Derechos Humanos, tal como lo consignaron organismos internacionales versados en la materia (Human Rights Watch, 2020; OEA, 2020).

Estos fenómenos, y especialmente su sucesión y continuidad, pueden ser entendidos bajo la idea de "acontecimiento". ¿Qué entendemos por acontecimiento? Desde Deleuze podemos pensarlo no como una interrupción de la vida, sino como su intensificación, que genera un ilimitado devenir. Así, un acontecimiento es aquello que acaba de suceder y lo que, al mismo tiempo, va a suceder, una síntesis entre pasado y futuro, en la que todo es presente (Deleuze, 2005). Este aspecto resulta relevante para marcar un aspecto subjetivo del estallido social: la temporalidad que instituye, una temporalidad de eterno presente.

En tanto eterno transcurrir, el estallido social, como acontecimiento, se revela a sí mismo como un objeto que urge ser pensado, pero que al mismo tiempo se resiste a ello. Acaso el mismo acto de pensar el acontecimiento se ve influenciado por sus características: en tanto eterno presente, el acontecimiento dificulta el que pueda ser pensado, y ello es ya una característica del acontecimiento que ha surgido a partir de que se pueda pensar. Con todo, es el acontecimiento que llamamos "estallido social chileno" el que es objeto de este estudio. Agregamos a él las características que lo pueden definir y el sujeto que produce, el que referiremos pronto como "sujeto de la protesta".

El carácter de objeto de estudio cambiante parece no haber sido tomado en cuenta en un estudio reciente, que enfatiza el carácter creativo de las expresiones de malestar en el contexto del estallido social 
chileno (Cares, 2019). Más bien, tomadas como artículos de museo, el artículo citado pareciese buscar elaborar una interpretación de carácter psicoanalítico de las manifestaciones artísticas surgidas en el estallido, considerando que estas se dieron en un momento acotado y sin considerar aspectos como su insistencia en ser registradas. Esta insistencia es, a nuestro juicio, un aspecto que remarca el carácter de eterno presente del acontecimiento del cual estas manifestaciones artísticas forman parte, entendidas ellas como representaciones del malestar.

Ensayamos un abordaje del estallido social que no soslaya los determinantes político-económicos del malestar, los que han sido documentados extensamente por Mayol desde 2011 y trabajados en su especificidad en Big Bang. El estallido social 2019 (Mayol, 2019). Trabajamos la problemática, sin embargo, considerando categorías de análisis que se refieren a su carácter socio-psíquico, bajo la construcción de un sujeto, el sujeto de la protesta, como el principal protagonista y producto del acontecimiento. Dicho sujeto, como pronto revisaremos, es entendido a partir de coordenadas psíquicas y es referido a lo social bajo las consideraciones de Cornelius Castoriadis respecto del estudio de lo social-histórico como objeto.

Cabe destacar que entendemos como "perspectiva psíquica" algo diverso que el abordaje de las consecuencias que la violencia estatal puede presentar para la salud mental. Esta dimensión ha sido ya suficientemente considerada a partir de la experiencia previa de instituciones públicas, como el Programa PRAIS con el trauma político (Madariaga, 2019). Más bien, el presente artículo trabaja sobre las características de un fenómeno social entramado con lo psíquico, en tanto lo psíquico puede explicar los esfuerzos por representar, en el espacio público, el malestar, y así informarnos sobre lo que lo causa y sus características.

\section{El sujeto de la protesta como producto del estallido social}

Recuperábamos a Deleuze para indicar que, en tanto acontecimiento, el estallido social instaura una temporalidad especial. ¿Quién es, sin embargo, el que hace experiencia de este acontecimiento y participa de esta temporalidad del eterno presente? Cabe considerar aquí la siguiente hipótesis: el acontecimiento ha visto el nacimiento de un 
nuevo sujeto, que llamamos "sujeto de la protesta". Aquí acompañamos a Rojas en lo que planteaba en 2006, a propósito de las protestas estudiantiles de ese año en Chile: "el sujeto colectivo que 'comunica' sus demandas generando determinados recursos representacionales, en sentido estricto no existe con anterioridad a la generación de esos recursos. Este sujeto se constituye en el lenguaje" (Rojas, 2006, p. 2). Lo que Rojas planteaba en 2006, respecto del sujeto que en ese año irrumpió en el espacio público, puede ser utilizado para pensar los esfuerzos representacionales con los que el sujeto de la protesta de 2019 ha irrumpido a propósito del estallido social. Podemos dejar para la historiografía el estudio acerca de si acaso el sujeto de 2006 es el mismo que el de 2019. Con todo, el sujeto de la protesta de 2019 se ha ocupado de nombrar su nacimiento, elaborando la consigna "Chile despertó". Como producto del acontecimiento, se constituye en un esfuerzo de escritura del malestar que ha sido permanente, pese a los borramientos de los recursos representacionales que ha empleado utilizando el espacio público como telón.

Este sujeto de la protesta, que deviene como tal a partir de sus recursos representacionales, requiere para su formalización que consideremos su carácter sociopsíquico. En tanto es un sujeto de la protesta, lo reconocemos como un actor del campo social. En tanto sujeto le reconocemos sus esfuerzos por otorgar al malestar posibilidades de ser representado. Le reconocemos, entonces, sus esfuerzos por otorgar representabilidad al malestar, destacando desde la perspectiva psicoanalítica su carácter psíquico.

¿Cómo un concepto originado a partir lo psíquico puede utilizarse para abordar un fenómeno de carácter social? Abordemos brevemente esta tensión psique-sociedad. Castoriadis se ocupará activamente del carácter social de los conceptos psicoanalíticos. Por un lado, nos dirá que, "en cuanto al psicoanálisis, el individuo que este encuentra es siempre un individuo socializado" (Castoriadis, 1997, p. 3). Yendo más allá, dirá incluso que los conceptos psicoanalíticos "son impensables, salvo en tanto productos (a lo sumo, coproducidos) del proceso de socialización" (Castoriadis, 1997, p. 3). Desde aquí podemos indicar, a propósito de la idea de "sujeto de la protesta", que la misma idea de sujeto es un producto del proceso de socialización, al tiempo que el sujeto psicoanalítico no es sino socializado. 
Por otro lado, el mismo Castoriadis declarará que "los individuos socializados son fragmentos hablantes y caminantes de una sociedad dada; y son fragmentos totales; es decir encarnan (...) el núcleo esencial de las instituciones y de las significaciones de su sociedad" (Castoriadis, 1997, pp. 3-4). Así, y a propósito de la idea de "sujeto de la protesta", entendemos que las significaciones sociales, aquellas que han dado el nombre de "estallido social" al acontecimiento que estamos abordando, se encarnan de manera total en cada uno de los sujetos que pertenece a lo que hemos llamado "sujeto de la protesta".

Es a partir de considerar estos elementos que la idea de "sujeto de la protesta" se permite acuñar, en una misma expresión, un concepto referido a lo individual - el sujeto-y otro referido a lo social - la protesta-, aprovechando en ello lo que el psicoanálisis puede pensar sobre el sujeto y refiriéndolo a un fenómeno de carácter social, sin dejar de pensar qué de lo social toma lugar en cada sujeto.

Luego de su nacimiento, y con la llegada de la pandemia por el virus SARS-CoV, este sujeto de la protesta parece haber transitado hacia un segundo momento: desde las lacrimógenas, las bombas incendiarias, las mutilaciones oculares y los fragmentos de pavimento lanzados como proyectil, hasta la suspensión de la escritura de su malestar en el espacio público. El sujeto de la protesta, estando recluido y siendo borroneado en sus recursos representacionales - y por lo tanto en su carácter de sujeto-, ha atestiguado cómo el manejo que el poder político económico ha hecho de la crisis sociosanitaria evidencia y profundiza las diferencias que lo habían llevado a elevar consignas por la dignidad.

Este segundo momento del sujeto de la protesta no deja de marcar el carácter incierto de su devenir, aspecto que forma parte de su constitución y presumiblemente de su futuro. Entendemos desde aquí un tercer momento de este sujeto, su retorno, el que podrá advenir terminada la pandemia por SARS-CoV, o quizás durante ella: la creación de un lenguaje con nuevos y distintos recursos representacionales - al decir de Rojas-, que busque representar en el espacio público un malestar siempre multívoco y acaso sobredeterminado (Freud, 1985).

Es a partir de la consideración del estallido social como acontecimiento, siguiendo en ello a Gilles Deleuze, y del abordaje del mismo 
hecho como fenómeno sociopsíquico, que arribamos a la consideración de uno de los productos del estallido: el sujeto de la protesta. Marcaremos ahora aspectos paradojales del estallido y de este sujeto que resultan relevantes para su descripción.

\section{Aspectos paradojales del estallido social y del sujeto de la protesta}

Entendemos que el estallido social, en tanto acontecimiento al que asistimos, corre en una temporalidad de eterno presente en una dirección que nos es desconocida. Existe en este aspecto una paradoja que es pertinente enunciar: sobre la dirección del devenir del acontecimiento solo sabemos que no sabemos. Este retroceso desde la clásica lógica de investigación - la que supone que puede llegar a generar algún conocimiento sobre algo- hasta la docta ignorancia de Sócrates y de Nicolás de Cusa, nos permite relevar otros aspectos del acontecimiento que también tienen un carácter paradojal.

1) Las fuerzas de seguridad han dispuesto que, en su propósito de combatir a la protesta, están permitidos la proyección de agua con químicos irritantes, el gaseamiento de sendas zonas residenciales empobrecidas, la violación sexual de mujeres y hombres, y otros actos de violencia de Estado. La violencia que con mayor fuerza se ha transformado en motivo para la protesta ha sido las múltiples mutilaciones oculares sufridas por manifestantes, lo que ha terminado en lo que para las víctimas es pérdida ocular y enceguecimiento, y para la protesta la oportunidad de ver qué es lo que está dispuesto a hacer el Estado para defenderse de los cambios que se demandan. Es una ceguera que permite ver y, bajo su carácter metafórico, este aspecto del estallido social tiene una estructura paradojal.

2) El sujeto de la protesta ha logrado, en el acto de la expresión de su malestar y -luego- de su representación, construir símbolos y consignas para significar su malestar. Entre ellos, "Chile despertó". Este símbolo no solo parece expresar algo relativo a un darse cuenta, si no que también anuncia que la protesta como sujeto ha hecho pensable una realidad social distinta a la que ha llevado al estallido. Quizás podamos enunciarlo así: “Chile despertó, y despertó para soñar". Este aspecto de acontecimiento tiene también un carácter paradojal, y su aprehensión se nos hace transparente desde la poe- 
sía, al igual que la anterior: despertar y soñar son expresiones contrapuestas que, comprendidas como componentes de una paradoja, adquieren un nuevo sentido, de carácter metafórico.

Esta paradoja, que da título al presente artículo, expresa un aspecto esencial de lo que abordamos: el sujeto de la protesta, que se ha tomado el espacio público para dar representabilidad a su malestar, ha logrado crear, a partir de su capacidad para la representación, un símbolo en forma de consigna, mediante el cual logra significarse a sí mismo y a su actuar. En sí mismo el símbolo tiene carácter paradójico: se despierta para soñar, y solo puede comprenderse involucrando lo que prontamente formalizaremos como una "lógica paradojal", a partir de la que se comprende la metáfora en la que es posible despertar y soñar a la vez.

3) Aun en tiempos en los que el sujeto de la protesta se encuentra recluido a causa del SARS-CoV, se nos hace transparente la insistencia del malestar social. No sin esperanza se augura que, terminada la cuarentena, el malestar vuelva a dar uso a los espacios y símbolos que ha construido. No sin acusaciones de provocación se condena el borramiento de la representación del malestar que ha construido el sujeto de la protesta. La insistencia de este malestar, que no deja de marcar el carácter de eterno presente del acontecimiento, aparece junto a otro fenómeno: la amplia tolerancia al desorden de los que participan de la protesta como observadores. El malestar que genera este mismo desorden se comenta, se sostiene, se tolera, y quizás en el futuro veremos que se atesora como un objeto histórico. Este es también un aspecto del estallido social y tiene un carácter paradojal: el malestar de la crisis es condición del bienestar futuro: el sufrimiento es el portavoz del bienestar.

4) En el espacio público, la protesta se construye a sí misma como sujeto, pero no puede sino estar compuesta por singularidades. Estos sujetos - múltiples, diversos-, que resisten a toda clasificación y suelen ser pensados como el sostén material de un movimiento al que se le ha dado el carácter de transversal, participan de la protesta mientras la sienten algo propio. Es más, encuentran, a partir de su pertenencia al sujeto de la protesta, algo que les pertenece como sujetos singulares. El carácter paradojal de ello viene dado por lo siguiente: el sujeto singular que participa de ese otro sujeto 
que llamamos la protesta, encuentra algo intrínsecamente propio en el lugar de lo común.

5) La violencia civil, aquella que marca el espacio urbano con el malestar que es su causa directa - y que es preciso entender como un aspecto ineludible del despertar-, puede ser descrita como una destrucción que busca ligar: construir un nuevo lazo social mediante la destrucción del espacio urbano. Otras formulaciones de la misma paradoja: hacerse escuchar mediante un grito ensordecedor; destruir el espacio común con la finalidad de hacerlo propio, de que le pertenezca a la protesta.

Este aspecto del acontecimiento tiene también un carácter paradojal y nos permite marcar un carácter relevante del modo como adquiere representación el malestar del sujeto de la protesta: el malestar busca sus posibilidades de representación mediante actos que pueden ser considerados violencia civil, pero que se comprenden a sí mismos, más bien, como un intento de descarga. Esta descarga del malestar es susceptible de devenir representación del malestar en caso de que lo descargado sea sostenido - y en buena medida soportado- por el espacio urbano. En ello, los muros incólumes y el duro pavimento del espacio público cumplen una función de sostén - al decir de Winnico$\mathrm{tt}-$ que no debe soslayarse. Se destruye la ciudad porque se sabe que, pese a todo, la ciudad sobrevivirá. Si sobrevive, entonces el sujeto de la protesta puede considerarla como propia, como un lugar para habitar. Significa que le pertenece al sujeto de la protesta y que la atesora, pero para eso tiene que destruirla primero, y que esta sobreviva.

Con la descripción de esta última paradoja inauguramos la consideración de estos aspectos paradojales del estallido social y del sujeto de la protesta, desde lo que entenderemos como "lógica paradojal" en la obra de Donald Winnicott.

\section{El estallido social y el sujeto de la protesta desde la lógica paradojal de D. Winnicott}

La ceguera que permite ver; despertar para soñar; el malestar que es condición del bienestar; la construcción de lo propio a partir de lo común; la destrucción que busca ligar. Estos aspectos paradojales del acontecimiento tienen la particularidad de estar definidos con afirma- 
ciones contrapuestas, y no faltará quien lea en ellos una contradicción y los juzgue como ilógicos.

Así parece haberse juzgado a la protesta en las expresiones de lo que la causa. Lo hemos escuchado en intelectuales, columnistas, psicoanalistas, varios de ellos consultados supuestos expertos y citados a la Presidencia de la República para asesorar con su divina compresión. Se han utilizado palabras como "condenar todos tipo de violencia", "delincuentes", "regresión de carácter temporal”, "pulsiones emocionales", "lo quieren todo gratis", "protesta carnavalesca y orgiástica", etc. Antes que artículos de carácter disciplinar, que exigirían un análisis más responsable, estas afirmaciones se han dado a la prensa escrita y a la televisión en los más variopintos formatos. Son afirmaciones proferidas por personas que tienen ya a su haber publicaciones de carácter disciplinar, lo que transforma sus denostaciones al sujeto de la protesta y a la expresión de su malestar en parte del mismo acontecimiento, pero constituyen su revés: buscan combatir desde el lugar de la razón a un sujeto que es denunciado como ilógico, visceral, orgiástico. Frente a ellos, este sujeto de la protesta se revela y se rebela en su sin razón como el revés de la razón, al modo como la locura de Foucault marcaba el carácter irracional de la razón (Foucault, 2009).

¿Desde dónde abordar, entonces, al sujeto de la protesta? No, ciertamente, desde la idea de "contradicción". Es necesario abordar desde otra concepción el por qué la protesta destruye lo común, cómo es que el malestar puede ser el antecedente de un futuro más auspicioso, por qué la ceguera ilumina el camino y qué significa que Chile haya despertado para soñar. Bajo la lógica clásica, solo puede observarse en la expresión del malestar una contradicción insalvable, lo que resulta en un análisis en absoluto adecuado.

Sostenemos que estas aparentes contradicciones pueden comprenderse distinto si incorporamos una lógica distinta a la clásica, una lógica paradojal. Según esta lógica, que puede ser más o menos familiar para quienes trabajamos desde el psicoanálisis, contradicción y paradoja no son sinónimos, si no que antónimos. Mientras que el principio de no contradicción, un principio básico de la lógica clásica, comprende como error el hecho de que existan dos afirmaciones contrapuestas entre sí, desde la paradoja podemos alojar estas dos afirmaciones bajo la idea de que se condicionan mutuamente. Una no es sin la otra. 
La lógica paradojal sería aquella que permite dar lugar a afirmaciones contrapuestas que se condicionan mutuamente.

Como psicoanalista, ha sido Donald Winnicott el que ha hecho de la lógica paradojal un aspecto central de su abordaje de lo psíquico (Winnicott, 1992). A partir de considerar que los opuestos solo son contradictorios bajo la lógica clásica, propia de la conciencia y del observador externo, logró describir con profundidad aspectos trascendentales del trabajo con pacientes gravemente perturbados y abordar aspectos de la constitución psíquica.

La lógica paradojal le permitió acercarse a fenómenos clínicos y del desarrollo que anteriormente recibían otras comprensiones, o que bien no habían sido identificados, permitiéndole construir una metapsicología del psiquismo distinta a las disponibles en su tiempo, distanciándose así de la primacía del mundo interno de Melanie Klein y del sometimiento a la realidad externa que proponía la Psicología del Yo de Anna Freud. A partir de considerar que fenómenos aparentemente opuestos se definieran según su mutua condicionalidad, es decir, a partir de la lógica de la paradoja, Winnicott logró darle un lugar a aspectos del psiquismo que no habían podido ser abordados desde otros modos de pensamiento al interior del psicoanálisis (Meneses, 2014).

Uno de los aspectos del psiquismo que Winnicott relevó a partir de una lógica paradojal consistió en el hecho de que el niño, y todo adulto a través de él, desarrolla la capacidad para estar solo a partir de la presencia de alguien. Mientras que soledad y compañía pueden constituir opuestos insalvables para otras comprensiones del psiquismo, para este autor se condicionan entre sí y no se anulan, si no que se condicionan mutuamente (Winnicott, 1965).

Otra paradoja sobre el desarrollo del psiquismo temprano que este autor logró abordar se da en el campo de qué es lo que sería una madre. Para él una madre es la que cumple funciones maternas, siempre y cuando también pueda fallar en cumplirlas (Winnicott, 1965). Como pediatra y psicoanalista, Winnicott comprendió muy tempranamente que, si la madre no falla, entonces falla en ser madre. Entendemos entonces que una madre es quien falla en serlo, aspecto paradojal que para este autor opera como condición del desarrollo temprano del psi- 
quismo humano. Madre y no-madre son afirmaciones opuestas que se condicionan mutuamente, sin anularse.

Winnicott también se preocupó de describir de manera paradojal cómo el psiquismo accede a la significación: para él, la relación del sujeto con la realidad está mediada por un espacio de ilusión posibilitado por la madre del bebé, el espacio transicional, en el cual aparece el objeto transicional, ese pedacito de tela o ese peluche que el bebé utiliza para dormir. Ese objeto es tanto interno como externo, y la madre sabe que no debe resolver la paradoja que lo funda: el objeto transicional es creado por el bebé y al mismo tiempo es descubierto afuera, en un mismo proceso (Winnicott, 1992). Es a partir de este espacio transicional, un espacio en el que reina la lógica paradojal, que el sujeto accede a la realidad externa sin perderse a sí mismo en ella, logrando significarla y hacerla propia.

Me parece que, si consideramos el modo paradojal como Winnicott abordó la capacidad para estar solo, la falla como función materna y el objeto transicional, podremos entregar una comprensión nueva a los fenómenos sociopolíticos a los que hoy asistimos, que algunos otros ven como contradicciones de la protesta.

La ceguera que permite ver; el despertar para soñar; el malestar que es condición del bienestar; la construcción de lo propio a partir de lo común; la destrucción que busca una ligadura. Al considerar estos aspectos del acontecimiento como paradojas, nos permitimos acceder a ellos desde una perspectiva metafórica, que aclara su comprensión: están formulados en un modo más cercano a la poesía que a la lógica clásica, y obtienen valor justamente en función de que resisten a una comprensión por la vía usual, exigiendo una lógica paradojal para su consideración.

Obtener desde el psicoanálisis de Winnicott, y específicamente de su metapsicología, la idea de lógica paradojal, permite remarcar el carácter psíquico del sujeto de la protesta, el carácter psíquico de un sujeto que es también social. Es un sujeto constituido por sujetos individuales y que puede llegar a representar en el espacio público un malestar de carácter social. En ello, como hemos marcado en un inicio, es fundamental considerar con Castoriadis que "sociedad y psique son a su vez irreductibles una a la otra, y realmente inseparables" (Casto- 
riadis, 1997, p. 4), imbricación desde la que hemos seleccionado a un autor de la psique, un psicoanalista, para considerar los aspectos psíquicos de un hecho social.

Junto con ello, desde un autor de la psique como Winnicott podemos abordar la cuestión de la representación del malestar, en la medida en que la insistencia del sujeto de la protesta por dejar huella y elaborar su malestar en el espacio público no solo es un fenómeno de carácter sociopolítico, sino también psíquico: mediante la representación no solo se expresa el malestar, también se elabora. Este malestar que, antes de ser representado, no contaba con representabilidad, la adquiere al momento de su representación. El sujeto de la protesta se encuentra, allí fuera, representado con lo que anteriormente no podía adquirir esa condición. Esta paradoja, en la que lo irrepresentable adquiere representabilidad a partir de la misma representación, fue también trabajada por Winnicott a propósito del fenómeno clínico del miedo al derrumbe (Winnicott, 1989), en el que aborda el problema de cómo un hecho de la realidad externa, que no ha podido tener lugar en términos psíquicos, puede adquirir representabilidad a partir de la experiencia de lo irrepresentable, bajo la profunda dependencia a la que el paciente se abandona en el tratamiento psicoanalítico, sostenida por el ambiente dispuesto para ello.

Quizás las especiales condiciones ambientales y de sostén que ofrece la clínica psicoanalítica tal como la comprende Winnicott, se parecen a los muros de nuestras ciudades: estables y sólidos escenarios en los que se puede plasmar, siempre de manera paradójica, es decir, mediante su destrucción, un malestar que adquiere representabilidad en el acto de ser expresado, sin haber tenido antes dicha posibilidad.

Considerado el carácter psíquico y paradojal del sujeto de la protesta, pasaremos ahora a discutir las posibilidades, consecuencias y destinos de las hipótesis elaboradas.

\section{A modo de discusión: la causa y las causas del sujeto de la protesta}

Podemos decir que el estallido social, especialmente en el carácter paradojal de los fenómenos en los que consiste y del sujeto que lo habita —el sujeto de la protesta-, opera según una lógica más cercana a la 
que el psicoanálisis ha utilizado para abordar el psiquismo temprano, que la que los intelectuales que asesoran a la Presidencia utilizan para abordar el fenómeno. ¿Cuál es la causa del estallido? Esta sola pregunta supone una lógica clásica que encadena causas a efectos. Existen antecedentes, facilitadores y desencadenantes, por supuesto. Pero ¿cómo podemos describir la causa última del estallido, si es un malestar que todavía no ha adquirido por completo su representabilidad?

Responder al asunto de la causa implicaría, a su vez, una búsqueda por apresurar y agotar la representación de un acontecimiento que todavía no deja de suceder, al tiempo que se le resta al sujeto de la protesta el derecho - ganado en el espacio público- de definir por sí mismo aquello que lo causa, digamos, sus causas, aquellos hechos políticos que podría enarbolar como banderas de lucha. Me parece que para abordar al sujeto de la protesta es necesario, en primer lugar, reconocer que será este sujeto por sí mismo el que construirá, por la vía del acto y el progresivo arribo a la palabra, sus causas.

Para decir esto es necesario pensar al sujeto de la protesta subvirtiendo la lógica clásica desde una lógica paradojal: no se trata de que las causas causen a los efectos, si no de que, a veces, especialmente cuando se trata de pensar el acontecimiento, el efecto precede a la causa. El sujeto de la protesta construye a posteriori lo que la causa, dado que en un inicio el malestar que lo motiva no ha adquirido todavía representabilidad. Lo adquiere después, en su propio devenir y en la relación con un ambiente que logra cumplir una acción de sostén. En esto sería fundamental jugar con el significante "causa", que sería aquello último que motiva a la protesta, el malestar a la base, y, al mismo tiempo, las demandas que, en el devenir del protestar, el sujeto de la protesta logra construir.

¿Qué rol podemos cumplir aquellos que investigamos y elaboramos sobre el acontecimiento? Escuchando a ese acontecimiento que llamamos "desarrollo psíquico temprano", Winnicott comprendió, desde la pediatría psicoanalítica, que las paradojas del desarrollo del psiquismo humano deben tolerarse en lugar de confrontarse o interpretarse, como se haría al considerarlas contradicciones. Es solo desde aquí que el bebé podrá hacer ingreso a la representación al modo en que lo elabora Winnicott, es decir, a la posibilidad de hacer propia la realidad y de sentir las experiencias como propias. 
En nuestra lectura psíquica del fenómeno social, podemos decir que el malestar que causa al sujeto de la protesta no podrá encontrar sus causas si no es a partir sostén físico que pueden otorgar los muros y el espacio público, ese incólume espacio de escucha que recibe la descarga de lo irrepresentable y le entrega representabilidad por la vía de su constante presencia. En este proceso sociopsíquico por encontrar su causa y sus causas, el sujeto podrá beneficiarse, en su camino hacia la representación, de la paciencia y escucha atenta de aquellos que buscan hacer sentido del estallido social chileno: no tanto para desentrañar y desenmascarar el supuesto sentido oculto del malestar, si no para tolerar cuánto de violento hay en su manifestación.

Nos queda tolerar las paradojas que definen al sujeto de la protesta, advirtiendo en ellas un proceso de representación en curso que el sujeto de la protesta tiene que recorrer por sí mismo. Para dar sostén a ese proceso, los que tenemos el interés y estamos en posición de hacerlo podemos abogar por que se otorgue a la protesta las condiciones para arribar a su causa y sus causas. Para ello, lo primero es no hacerle la guerra, pero tampoco denostar sus medios de expresión, que son las vías por las cuales ella podrá encontrarse como sujeto y, al mismo tiempo, hacerse escuchar.

\section{Referencias}

Cares, F. (2019). Estallido social en Chile: imágenes que exigen dignidad. Conferencia Internacional de Cultura Visual.

Castoriadis, C. (1997). El imaginario social instituyente. Revista Zona Erógena, 35, 1-9.

Deleuze, G. (2005). Lógica del sentido. Buenos Aires: Paidós.

Foucault, M. (2009). Historia de la locura en la época clásica. Buenos Aires: Fondo de Cultura Económica.

Freud, S. (1895). Estudios sobre la histeria: comunicación preliminar. En Obras Completas, Tomo II. Buenos Aires: Amorrortu.

Human Rights Watch. (20 de marzo de 2020). Informe Mundial 2020, Chile, Eventos 2019. Recuperado de https://www.hrw.org/ es/world-report/2020/country-chapters/337307

Madariaga, C. (2019). El "estallido social" y la salud mental de la ciudadanía. Una apreciación desde la experiencia PRAIS. Revista Chilena de Salud Pública, 23(2), 146-156. 
Mayol, A. (2019). Big bang. Estallido social 2019. Modelo derrumbadoSociedad rota - Política inútil. Santiago de Chile: Catalonia.

Meneses, P. (2014). Elementos Metapsicológicos en la obra de Donald Winnicott. Tesis de Magíster, Universidad de Chile.

Organización de Estados Americanos. (20 de marzo de 2020). CIDH condena uso excesivo de fuerza en el contexto de las protestas sociales en Chile. Obtenido de http://www.oas.org/es/cidh/ prensa/comunicados/2019/317.asp

Rojas, S. (2006). Estética del malestar y expresión ciudadana. Hacia una cultura crítica. Seminario "Ciudadanía, Participación y Cultura". Consejo Nacional de la Cultura, Centro Cultural Palacio La Moneda.

Winnicott, D. (1965). Los procesos de maduración y el ambiente facilitador. Barcelona: Paidós.

Winnicott, D. (1989). Exploraciones psicoanalíticas I. Buenos Aires: Paidós.

Winnicott, D. (1992). Realidad y Juego. Buenos Aires: Gedisa. 